\title{
Perfil epidemiológico dos casos com microcefalia atendidos em maternidade de alto risco em Sergipe
}

\author{
Epidemiological profile of cases with \\ microcephaly served in high-risk \\ maternity in Sergipe
}

\author{
Andria Silveira Almeida' ${ }^{1}$ \\ Elaine Ferreira da Silva ${ }^{2}$ (1) \\ Ravena dias Figueredo Rodrigues dos Santos ${ }^{3}$ (1)
}

\section{Thaynara Fontes Almeida 4 (1) Fernanda Kelly Fraga Oliveira ${ }^{5}$ (1) Lourivânia Oliveira Melo Prado ${ }^{6}$ (1)}

${ }^{1}$ Autora para correspondência. Universidade Tiradentes (Aracaju). Sergipe, Brasil. andria-almeida@hotmail.com

2-6Universidade Tiradentes (Aracaju). Sergipe, Brasil. enfa.elaineferreira@hotmail.com, ravenna07@hotmail.com, thaynarafontess@gmail.com, fernandadaponte@hotmail.com, loriorado@bol.com.br

RESUMO | OBJETIVO: Delinear o perfil epidemiológico dos casos atendidos com microcefalia em uma maternidade de alto risco no estado de Sergipe no ano de 2015. MATERIAIS E MÉTODOS: Trata-se de um estudo descritivo quantitativo dos casos de microcefalia em nascidos vivos de mães residentes no estado de Sergipe. Foi desenvolvido em uma maternidade pública de referência para gestantes e recém-nascidos de alto risco do município de Aracaju - Sergipe. A amostra selecionada por conveniência foi composta por 57 prontuários de casos de recém-nascidos microcefálicos. RESULTADOS: Em relação ao perfil dos recém-nascidos, $56,14 \%$ eram do sexo feminino, $85,96 \%$ tinham perímetro cefálico $<32 \mathrm{~cm}, 82,45 \%$ Ápgar1 ` $\geq 7$, $92,98 \%$ Ápgar $5 \geq 7$ e $82,45 \%$ peso normal (2500-3999g). Quanto às características sociodemográficas das genitoras, $49,12 \%$ tinham entre 21 a 30 anos, 96,49\% raça/cor parda, 26,3\% ensino fundamental incompleto e $77,19 \%$ ocupação de doméstica. Durante o pré-natal, 8,77\% realizaram exames de STORCH, $7,01 \%$ o exame de zika vírus, $8,77 \%$ exame para chikungunya e 3,50\% sorologia para dengue. Em 2015, a microcefalia no estado foi considerada emergência de importância nacional. CONCLUSÃO: Houve predomínio de recém-nascido do sexo feminino e com perímetro cefálico <32. A maioria das genitoras eram adultas e com baixas condições socioeconômicas.

DESCRITORES: Epidemiologia. Microcefalia. Zika vírus. Mães. Recém-nascido.
ABSTRACT | OBJECTIVE: To outline the epidemiological profile of cases treated with microcephaly in high-risk maternity in the state of Sergipe in 2015. MATERIALS AND METHODS: This is a quantitative descriptive study of microcephaly cases in live births of mothers living in the state from Sergipe. It was developed in public maternity of reference for pregnant women and high-risk newborns in Aracaju- Sergipe's municipality. The convenience-selected sample consisted of 57 medical records of cases of microcephalic newborns. RESULTS: Regarding the profile of the newborns, $56.14 \%$ were female, $85.96 \%$ had head circumference $<32 \mathrm{~cm}, 82.45 \%$ Ápgar1 ${ }^{`} \geq 7,92.98 \%$ Ápgar $5 \geq 7$ and $82,45 \%$ normal weight (2500-3999g). As for the mothers' sociodemographic characteristics, $49.12 \%$ were between 21 and 30 years old, $96.49 \%$ race/brown color, $26.3 \%$ incomplete elementary school, and $77.19 \%$ occupation of housework. During prenatal care, $8.77 \%$ underwent STORCH tests, $7.01 \%$ underwent Zika virus testing, $8.77 \%$ underwent chikungunya, and $3.50 \%$ serology for dengue. In 2015, microcephaly in the state was considered an emergency of national importance. CONCLUSION: There was a predominance of female newborns with head circumference $<32$. Most of the mothers were adults and had low socioeconomic conditions.

DESCRIPTORS: Epidemiology. Microcephaly. Zika virus. Mothers. Newborn. 


\section{Introdução}

O zika vírus pertence ao gênero flavivírus, é transmitido pelo mosquito Aedes Aegypti, e em 2015 foi identificado um surto do mesmo no Nordeste brasileiro 1,2 . Em setembro de 2015 houve um aumento do número de recém-nascidos com microcefalia em áreas afetadas por esta arbovirose ${ }^{3}$.

A microcefalia é definida através das alterações de estrutura física e funcional ao nascer. Segundo a Organização Mundial da Saúde (OMS) e literatura científica internacional, tem-se um caso considerado microcefalia quando o perímetro cefálico $(P C)$ for menor que dois ou mais desvios-padrão (DP) do que a referência para o sexo, idade ou tempo de gestação ${ }^{4}$.

De acordo com a Organização Pan-Americana (OPAS), de janeiro de 2015 a 2018 foram registrados 3.720 casos confirmados de Síndrome Congênita do Vírus Zika no território das Américas ${ }^{1}$. O Ministério da Saúde (MS), entre 2015 a 2018, notificou 16.348 casos suspeitos de alterações no crescimento e desenvolvimento, possivelmente relacionados à infecção. Desses, 3.226 (19,7\%) foram confirmados².

No Brasil, até fevereiro de 2016, foram notificados 5.909 casos de microcefalia, desse valor, 641 estiveram confirmados para algum tipo de anomalia, 139 evoluíram para óbito fetal ou neonatal, 96 permaneceram em investigação, 31 confirmados e 12 tiveram o diagnóstico de microcefalia descartado ${ }^{5}$. A maior prevalência se concentra na região Nordeste (59,3\%), seguida pela região Sudeste $(24,7 \%)^{6}$. No âmbito estadual, Pernambuco lidera com 21,3\%, Bahia 14,3\%, Paraíba 9,0\%, São Paulo 8,1\% e Rio de Janeiro 7,8\%?.

Comparando os dados sobre os casos de microcefalia de 2010 a 2014 com os dados entre 2015 e 2016, houve 150 casos relatados por ano no país, e hoje, os casos suspeitos totalizam em 13.835, destes, 2.753 $(19,9 \%)$ foram confirmados ${ }^{8}$.

Em Sergipe, foram notificados 274 casos suspeitos para síndrome congênita relacionada ao Zika entre os anos de 2015 a 2017, sendo 129 confirmados.
A região de Aracaju aparece com maior número de casos notificados (98), seguida pelas regiões de Nossa Senhora do Socorro (43), Estância (37) e Itabaiana (29) $2-9$.

A associação entre o Zika e a microcefalia surgiu a partir de achados do vírus no tecido cerebral dos recém-nascidos, através dos exames de imagens. No Brasil, em 2015 a rápida propagação tem centrado atenção das autoridades em saúde para possível diagnóstico e intervenção precoce em gestantes e neonatos infectados ${ }^{10}$.

Ressalta-se que o perfil epidemiológico do binômio mãe-filho com a síndrome congênita vírus Zika é importante, pois possibilita melhor entendimento acerca dos padrões de ocorrência da doença e das lacunas na prevenção, permitindo um melhor embasamento das estratégias para a assistência em saúde ${ }^{6}$.

Sendo assim, a pesquisa foi motivada devido à elevada incidência dos registros de microcefalia em recémnascidos e por se apresentar como grave problema de saúde pública em Sergipe. Tendo como objetivo delinear o perfil epidemiológico dos casos atendidos com microcefalia em uma maternidade de alto risco no estado Sergipe no ano de 2015.

\section{Materiais e métodos}

Trata-se de um estudo descritivo com abordagem quantitativa dos casos de microcefalia em nascidos vivos de mães residentes no estado de Sergipe.

O estudo foi realizado em uma maternidade, localizada na cidade de Aracaju-Sergipe e constitui-se como a única pública de referência do estado para gestantes e recém-nascidos de alto risco. Desde a sua inauguração, em dezembro de 2007, ela é colaboradora oficial do Estudo Colaborativo Latino-Americano de Malformações Congênitas (ECLAMC). Atende pacientes dos 75 municípios do estado, por meio de encaminhamentos ou por demanda espontânea e foi escolhida por ser base de dados populacionais de referência para o estado de Sergipe. 
A referente pesquisa faz parte de um projeto guarda-chuva intitulado como "Análise clínica e Epidemiológica dos casos de Microcefalia ocorridos em uma maternidade pública do estado de Sergipe" aprovado pelo Comitê de Ética e Pesquisa (CEP) da Universidade Tiradentes sob número do protocolo 2.583 .623 e do Certificado de Apresentação/Apreciação Ética (CAAE) 8334518.3.0000.5371. O estudo está de acordo com as diretrizes e normas regulamentadoras da Resolução 466/2012 do Conselho Nacional de Saúde, que fala sobre pesquisas envolvendo seres humanos.

A amostra selecionada por conveniência foi composta por 57 prontuários de casos de recém-nascidos microcefálicos durante o ano de 2015. Foram incluídos na pesquisa prontuários de recém-nascidos que apresentaram casos notificados e confirmados de microcefalia nascidos no período de 2015 arquivados no setor de arquivo médico (SAME) da instituição. Foram excluídos prontuários que não contemplavam as variáveis descritas na pesquisa. Os dados foram coletados através do formulário de notificação compulsória padronizado pelo MS e a ficha de registro de avaliação das condições de saúde da criança com microcefalia adaptada do protocolo de orientação do MS.

A coleta de dados ocorreu entre os meses de agosto a dezembro de 2018. O tempo médio para análise foi de 15 minutos para cada prontuário em função da ilegibilidade e interpretação dos dados. Dentre as variáveis para realizar essa pesquisa estão: variáveis do RN (sexo, Ápgar1, Ápgar5, peso, perímetro cefálico, alterações nos exames de imagem) e das mães (faixa etária, raça/cor, escolaridade, ocupação, situação conjugal e local de moradia).

Foi realizada uma análise descritiva por meio de frequência absoluta e relativa percentual. O software utilizado para análise estatística foi o R Core Team2018.

\section{Resultados}

O perfil e as condições clínicas dos 57 recém-nascidos microcefálicos no ano de 2015 estão descritos na tabela 1. Observou-se que houve predominância do sexo feminino 32 (56,14\%). O Apgar1' com valores $\geq 7$ teve uma prevalência de 47 (82,45\%) e Apgar $5^{\prime}$ com valor $\geq 7$ de 53 (92,98\%). Em relação aos dados antropométricos, foi identificado que 47 (82,45\%) apresentaram o peso normal (2500-3999g). Observou-se que 49 (85,96\%) tinham PC $<32 \mathrm{~cm}$ e $32(56,1 \%)$ microcefalia constatada pelos exames de imagem.

Tabela 1. Perfil e condições clínicas dos recém-nascidos microcefálicos no ano de 2015, Aracaju/SE

\begin{tabular}{|c|c|c|}
\hline Variáveis & & \\
\hline Sexo & $\mathbf{n}$ & $\%$ \\
\hline Feminino & 32 & 56,14 \\
\hline Masculino & 25 & 43,85 \\
\hline \multicolumn{3}{|l|}{ Ápgar1 } \\
\hline$<7$ & 10 & 17,54 \\
\hline$\geq 7$ & 47 & 82,45 \\
\hline \multicolumn{3}{|l|}{ Ápgar5 ` } \\
\hline$<7$ & 04 & 7,01 \\
\hline$\geq 7$ & 53 & 92,98 \\
\hline \multicolumn{3}{|l|}{ Peso } \\
\hline Muito baixo peso (1000-1499g) & 02 & 3,50 \\
\hline Baixo peso (1500-2499g) & 08 & 14,03 \\
\hline Normal (2500-3999g) & 47 & 82,45 \\
\hline \multicolumn{3}{|l|}{ Perímetro Cefálico } \\
\hline$<32$ & 49 & 85,96 \\
\hline$>32$ & 08 & 14,03 \\
\hline \multicolumn{3}{|l|}{ Alterações nos exames de imagem } \\
\hline Microcefalia & 32 & 56,14 \\
\hline Outras malformações & 19 & 33,33 \\
\hline Nenhuma alteração & 06 & 10,52 \\
\hline
\end{tabular}


Em relação às características sociodemográficas das genitoras correlacionada à faixa etária, a maioria apresentava idade entre 21 a 30 anos 28 (49,12\%). Declararam-se de raça parda 55 (96,49\%). Quanto ao nível de escolaridade, o de maior predominância foi o ensino fundamental incompleto com 15 (26,31\%). No que se refere à ocupação, predominou-se a opção de doméstica com 44 (77,19\%), e as demais características sociodemográficas estão descritas na tabela 2.

Tabela 2. Descrição das características sociodemográficas das mães de recém-nascidos com microcefalia no ano de 2015, Aracaju/SE

\begin{tabular}{|c|c|c|}
\hline Variáveis & n & $\%$ \\
\hline \multicolumn{3}{|l|}{ Faixa etária } \\
\hline $10-20$ anos & 16 & 28,07 \\
\hline $21-30$ anos & 28 & 49,12 \\
\hline 31 a 40 anos & 12 & 21,07 \\
\hline 41 anos e mais & 01 & 1,75 \\
\hline \multicolumn{3}{|l|}{ Raça/cor } \\
\hline Parda & 55 & 96,49 \\
\hline Preta & 01 & 1,75 \\
\hline Branca & 01 & 1,75 \\
\hline \multicolumn{3}{|l|}{ Escolaridade } \\
\hline Fundamental Completo & 07 & 12,28 \\
\hline Fundamental Incompleto & 15 & 26,31 \\
\hline Fundamental I & 02 & 3,50 \\
\hline Fundamental II & 11 & 9,29 \\
\hline Médio Completo & 10 & 17,54 \\
\hline Médio Incompleto & 08 & 14,03 \\
\hline Superior Incompleto & 03 & 5,26 \\
\hline Ignorado & 01 & 1,75 \\
\hline \multicolumn{3}{|l|}{ Ocupação } \\
\hline Doméstica & 44 & 77,19 \\
\hline Estudante & 03 & 5,26 \\
\hline Outros & 10 & 17,54 \\
\hline \multicolumn{3}{|l|}{ Situação conjugal } \\
\hline Solteira & 38 & 66,66 \\
\hline União estável & 12 & 21,05 \\
\hline Casada & 07 & 12,28 \\
\hline \multicolumn{3}{|l|}{ Local de moradia } \\
\hline Capital & 47 & 82,45 \\
\hline Interior & 10 & 17,54 \\
\hline
\end{tabular}

A tabela 3 descreve os achados sobre as realizações de exames laboratoriais durante a assistência no pré-natal. Foi verificado que apenas $5(8,77 \%)$ realizaram exames de STORCH, 4 (7,01\%) fizeram o exame de zika vírus, 5 $(8,77 \%)$ realizaram para chikungunya e $2(3,50 \%)$ realizaram sorologia para dengue.

Tabela 3. Exames laboratoriais realizados durante assistência no pré-natal, Aracaju/SE em 2015

\begin{tabular}{lll}
\hline \multicolumn{1}{c}{ Exames } & N & \% \\
\hline Zika vírus & 04 & 7,01 \\
STORCH & 05 & 8,77 \\
Chikungunya & 05 & 8,77 \\
Dengue & 02 & 3,50 \\
\hline
\end{tabular}

Fonte: Maternidade Nossa Senhora de Lourdes (2018). 


\section{Discussão}

As condições clínicas dos RNs, e as evidências encontradas nesse estudo concernem com um estudo realizado entre os anos de 2015 e 2016 no Piauí que foi publicado em 2018 , onde $21 \%$ desta população eram do sexo feminino, O PC medido após 48 horas do parto teve mediana de 33 centímetros (IIQ=3). A mediana de peso foi de 2.372 gramas (IIQ=712). Segundo MS os seguintes critérios para identificação do RN de risco são: baixo nível socioeconômico da família, mãe adolescente ( $<20$ anos), RN com baixo peso ao nascer $(<2.500 \mathrm{~g})$, mãe com baixa instrução (<oito anos de estudo), RN com asfixia grave ao nascer (Apgar $<7$ no $5^{\prime}$ ) e RN com outras doenças graves ${ }^{11}$.

Considera-se a criança com quadro de asfixia quando esta apresenta índice de Apgar menor $<7$ no $5^{\prime}$. Neste estudo, a maior prevalência foi entre o Apgar $\geq 7$ sendo $92,98 \%$ (53), portanto, não se considera risco para asfixia. Contudo, o escore de Apgar reflete as funções vitais do RN e, isoladamente, não é mais aceito para definir a asfixia ${ }^{12}$. Ainda assim, o escore de Apgar é considerado um importante indicador por sua fácil aplicabilidade. Quando se encontra $<7$ no 5', demonstra a necessidade de atenção especial ${ }^{13}$.

Quanto ao PC, foi revelado pela pesquisa que a maioria possui medida $<32 \mathrm{~cm}$. Segundo a OMS, a microcefalia é denominada com PC menor que -2 desvios- padrão ( $P C<-2 D P)$. É descrita como uma MC de comprometimento neurológico que tem como condições o não desenvolvimento do encéfalo adequadamente e o PC aferido no RN é inferior ao esperado para a idade gestacional e o sexo correspondente ${ }^{14}$.

O presente estudo mostrou que de acordo com as características sociodemográficas das genitoras de recém-nascidos com microcefalia no ano de 2015, houve predomínio de mães com idade de 21 a 30 anos com $(49,12 \%)$ ( $n 28)$, enquanto que o percentual de mães adolescentes com idade inferior a 20 anos foram de $28,07 \%$ (n 16), período que coincide com a idade reprodutiva da mulher.

No tocante à escolaridade, mulheres com menor grau de instrução tiveram maior número de RNs com microcefalia, com (26,31\%) (n 15). Ressalta-se que as mulheres menos instruídas foram as maiores vítimas, sendo evidenciada uma forte relação com o padrão socioeconômico, visto que estas pertencem a classes sociais mais baixas, podendo comprometer a gravidez e o desenvolvimento do bebê por diversas condições $\frac{15}{}$. Nota-se que o nível de escolaridade interfere diretamente no discernimento das informações pertinentes sobre a gestação, incluindo desde a realização do pré-natal conforme preconizado pelo MS, sendo no mínimo seis consultas, e ao cumprimento das orientações a respeito da prevenção das anomalias congênitas, principalmente a microcefalia.

Partindo do pressuposto de que o Brasil é um país de intensa desigualdade social, a pobreza pode ser considerada como um determinante social na configuração da epidemia de Zika vírus no país. As desigualdades sociais na saúde são explicadas pela teoria da determinação social do processo saúde-doença. São estudadas características sociais, como renda, ocupação, raça, etnia, gênero e condições do local de moradia. A organização social define a doença e sua distribuição a partir da posição de classe e da reprodução social, que passam a ser vistas como determinantes do perfil da saúde e doença ${ }^{16}$.

Outro fator determinante dá-se pelo acesso restrito aos serviços de saúde, principalmente para aquelas genitoras que residem em cidades do interior do estado, onde não se aplica ao resultado encontrado da pesquisa, tendo a capital como maior prevalência 47 $(82,45 \%)$, possibilitando maior qualidade na assistên$\mathrm{cia}^{16}$. Este número pode representar ainda o fato da capital dispor de uma rede de saúde de referência que atendeu as mulheres referenciadas do interior, que podem ter sido registradas erroneamente como residentes na capital sergipana.

Quanto à ocupação dessas mães, a maioria é de domésticas, o que demonstra que se dedicam integralmente ao cuidado da criança, o que pode se configurar em situações de abandono de suas atividades profissionais ou educacionais. Estudo destaca o papel da mulher como principal cuidadora ${ }^{17}$. No tocante a essa problemática, quando um dos pais, principalmente a mãe, tem a necessidade de deixar o trabalho para se dedicar ao cuidado da criança, consequentemente agrava a condição socioeconômica do grupo familiar. Diante dessa realidade, essas condições são decisivas no desenvolvimento humano, tornando-se necessário o conhecimento do contexto familiar e social no qual a criança está inserida. 
O presente estudo demonstrou predomínio para mães solteiras. Nesse sentido, o apoio familiar e, principalmente, do companheiro é fundamental durante a gestação e puerpério, pois são períodos de intensas alterações hormonais em que a mulher necessita de apoio psicológico, conforto e amparo. Um estudo realizado pelos acadêmicos do Curso de Medicina da Universidade Católica de Brasília no ano de 2013 também aponta que mulheres que não possuem companheiro tiveram mais casos de RN com microcefalia ${ }^{18}$. Houve ainda as situações de abandono, por parte do homem, da relação conjugal após diagnóstico de microcefalia da criança.

A criança portadora de microcefalia necessita de cuidados especiais, além da demanda de uma criança nascida saudável. Ela precisa de tratamento e acompanhamento de uma equipe multiprofissional para auxiliar na sua recuperação e desenvolvimento. Logo, o fato da maioria das mulheres estarem solteiras nestas situações, configura-se como uma vulnerabilidade à criança, pois a mãe além de ter a renda comprometida por causa do abandono das atividades de trabalho, fica sobrecarregada com os cuidados à criança.

A maior prevalência de detecção dessa anomalia foi diagnosticada durante a gestação. Segundo um estudo realizado em Cambridge em 2013, a detecção da microcefalia ocorre antes das 36 semanas, isso é devido à diminuição ou falha da neurogênese que são processos degenerativos ou agressões que influenciam no desenvolvimento e função do sistema nervoso central ${ }^{19}$.

Atualmente o diagnóstico por imagem é feito através da ultrassonografia transfontanelar para o reconhecimento de anomalias estruturais do cérebro, sendo recomendado quando o tamanho da fontanela for suficiente, sendo primordial para diagnóstico da microcefalia primária, e a tomografia computadorizada quando houver a forma grave, por ser mais específica ${ }^{11}$.

No caso de identificação precoce de uma circunferência craniana menor que o esperado para a idade gestacional durante o período do pré-natal, é possível alcançar maior êxito nas ações de esclarecimento das suspeitas epidemiológicas relacionadas à microcefalia, bem como preparar melhor e orientar de maneira adequada a família para o nascimento de um RN com malformação .
Segundo o MS, o pré-natal é um conjunto de maior relevância para os cuidados voltados à saúde materna e do feto, pois possibilita realização de ações e orientações que promovem uma boa vivência durante a gestação e parto, diminuindo os riscos de complicações no parto e puerpério. Durante o pré-natal, é possível evitar, detectar ou tratar a maior parte dos problemas de saúde das gestantes por meio de consultas ${ }^{4}$. O protocolo do MS recomenda a realização da coleta de amostras de sangue do cordão umbilical, líquido cefalorraquidiano (LCR) e urina do RN no momento do nascimento para realização de sorologias especificas para arboviroses e outras doenças do protocolo de investigação STORCH (sífilis, toxoplasmose, rubéola, citomegalovírus, herpes simplex)².

Devido à elevada incidência dos casos de microcefalia no ano de 2015, o MS, diante dessa epidemia, declarou estado de emergência de importância nacional, e constatou que os primeiros meses de gestação das crianças que nasceram com essa anomalia correspondem ao período de maior circulação do vírus zika, havendo correlação com histórico de doença genética na família ou exames com padrões de infecções para síndrome STORCH, justificando a necessidade da solicitação de exames durante opré-natal20.

De acordo com um estudo realizado numa maternidade de alto risco no estado de Sergipe em 2015, foram internadas 22 crianças (38,59\%) com desfecho clínico para microcefalia, ano de maior incidência para essa anomalia. Outro estudo realizado em uma maternidade de alto risco em Pernambuco no mesmo ano descreveu 29 casos de crianças com microcefalia internadas, levando a Secretária de Saúde do Estado de Pernambuco (SES-PE) a comunicar a existência da epidemia ao MS. Diante disso, as equipes da SES-PE juntamente com a Equipe do Programa de Treinamento em Epidemiologia Aplicada aos Serviços do Sistema Único de Saúde (EPISUS) iniciaram uma investigação epidemiológica preliminar doscasos 21 .

Diante do levantamento de dados com relação ao perfil epidemiológico da genitora, percebe-se que há vulnerabilidade do binômio mãe-filho, tornando-se necessária uma assistência holística e multidisciplinar pela rede de saúde, tendo a Atenção Primária à Saúde como elo principal nas ações de visitas domiciliares com foco na promoção, prevenção e manutenção no processo saúde doença. 
As limitações foram em relação aos prontuários, pois apresentavam ilegibilidade, o que dificultava análise e interpretação dos dados.

\section{Conclusão}

Houve um predomínio de recém-nascido do sexo feminino e com $<32 \mathrm{~cm}$ de $P C$, e em relação às genitoras, a maioria são adultas, da cor parda., com nível de escolaridade predominante de ensino fundamental incompleto e a maioria com ocupação de doméstica.

Ressalta- se que os RNs com microcefalia necessitam de cuidados de uma equipe multiprofissional para ajudar no seu crescimento e desenvolvimento. Os dados obtidos na pesquisa podem contribuir para a comunidade científica e para os profissionais que fazem o acompanhamento terapêutico dessas crianças, fornecendo informações sobre as condições clínicas, condições sociodemográficas e familiares. Para isso, considera-se relevante a realização de cursos de capacitação dos profissionais da saúde na identificação e notificação, objetivando melhorar o sistema de informações, e, dessa forma, estabelecer programas de saúde adequados para sua prevenção e assistência.

A pesquisa apresenta relevância visto que a microcefalia é um problema de saúde pública e por ser uma síndrome descoberta recentemente, necessita que novas pesquisas sejam desenvolvidas.

\section{Contribuições dos autores}

Silva EF e Santos RFR participaram da Concepção, delineamento, análise e interpretação dos dados e redação do artigo. Almeida TF e Oliveira FKF colaboraram na revisão crítica. Almeida AS participou na análise e interpretação dos dados, redação do artigo, revisão crítica e aprovação da versão a ser publicada. Prado LOM participou na concepção, delineamento, análise e interpretação dos dados, redação crítica do artigo e aprovação da versão final a ser publicada.

\section{Conflitos de interesses}

Nenhum conflito financeiro, legal ou político envolvendo terceiros (governo, empresas e fundações privadas, etc.) foi declarado para nenhum aspecto do trabalho submetido (incluindo, mas não se limitando a subvenções e financiamentos, participação em conselho consultivo, desenho de estudo, preparação de manuscrito, análise estatística, etc.).

\section{Referências}

1. Organização Pan-Americana da Saúde/Organização Mundial da Saúde (OPAS/OMS). Atualização epidemiológica -26 Janeiro de 2017 [Internet]. PAHO/WHO; 2017. Disponível em: https:// www.paho.org/bra/images/stories/SalaZika/atualizacao\%20032. pdf?ua=1

2. Ministério da Saúde (Brasil). Protocolo de Atenção à Saúde e resposta à ocorrência de microcefalia. Plano Nacional de Enfrentamento à Microcefalia [Internet]. Brasília: Ministério da Saúde; 2016. Disponível em: http://bvsms.saude.gov.br/bvs/ publicacoes/protocolo resposta microcefalia relacionada infeccao_virus_zika.pdf

3. Facinni LS, Ribeiro EM, Feitosa IML, Horovitz DDG, Cavalcanti DP, Pessoa A, et al. Possible association between Zika virus infection and microcephaly - Brazil, 2015. Morb. Mortal. Wkly. Rep. 2016;65(3):59-62. http://dx.doi.org/10.15585/mmwr. mm6503e2

4. Ministério da Saúde (Brasil). Protocolo de Atenção à Saúde e resposta à ocorrência de microcefalia relacionada à infecção pelo vírus zika. Plano Nacional de Enfrentamento à Microcefalia [Internet]. Brasília: Ministério da Saúde; 2015. Disponível em: https://portalarquivos2.saude.gov.br/images/pdf/2015/ dezembro/09/Microcefalia---Protocolo-de-vigil--ncia-e-resposta--vers--0-1----09dez2015-8h.pdf

5. Sousa PSA, Faria MD, Costa JR, Lira ELB, Leite AMC, Carvalho LL. Microcefalia e zika vírus: uma revisão sistemática. Rev Enferm UFPI. 2016;5(4):51-4. https://doi.org/10.26694/reufpi.v5i4.5347

6. Ministério da Saúde (Brasil), Secretaria de Vigilância em Saúde. Boletim epidemiológico. Monitoramento integrado de alterações no crescimento e desenvolvimento relacionados à infecção pelo vírus Zika e outras etiologias infecciosas, até a Semana Epidemiológica 30 de 2018. Brasília: Ministério da Saúde / Secretaria de Vigilância em Saúde. Disponível em: https:// portalarquivos2.saude.gov.br/images/pdf/2018/junho/29/ Monitoramento-integrado-de-alteracoes-no-crescimento-edesenvolvimento-relacionadas-a-infeccao-pelo-virus-Zika.pdf

7. Ministério da Saúde (Brasil), Secretaria de Vigilância em Saúde. Boletim epidemiológico. Monitoramento integrado de alterações no crescimento e desenvolvimento relacionados à infecção pelo vírus Zika e outras etiologias infecciosas, da Semana Epidemiológica 45/2015 até a Semana Epidemiológica 02/2017. Ministério da Saúde / Secretaria de Vigilância em Saúde; 2017. Disponível em: http://portalarquivos.saude.gov.br/images/ pdf/2017/fevereiro/27/2017_003.pdf

\footnotetext{
8. França GVA, Pedi VD, Garcia MHO, Carmo GMI, Leal MB, Garcia LP. Síndrome congênita associada à infecção pelo vírus Zika em nascidos vivos no Brasil: descrição da distribuição dos casos notificados e confirmados em 2015-2016. Epidemiol. Serv. Saúde. 2018;27(2):e2017473. https://doi.org/10.5123/s1679$\underline{49742018000200014}$
} 
9. Secretaria do Estado da Saúde-SES. Coordenação de Epidemiologia e Informação-INFORME EPIDEMIOLÓGICO ANO II № 02 [Internet]. Governo de Sergipe - Núcleo Estratégico da SES NEST. Aracaju, 2017. Disponível em: https://www.saude.se.gov.br/ wp-content/uploads/Informe-Semanal-n\%C2\%BA-02-micro-chikdengue-e-Zika_16.01.2017.pdf

10. Brito LB, Rastely Junior VN, Browne ES, Nery Júnior NRR, Sacramento GA, Costa F. Sinais e sintomas de zika-virus em gestantes internadas em um Hospital Público de referência da Bahia [Internet]. Congresso da Sociedade Brasileira de Medicina Tropical; 2016; Maceió. Disponível em: https://www.arca.fiocruz. br/handle/icict/18002

11. World Health Organization. Zika virus microcephaly and guillain-barré syndrome [Internet]. Organisation mondiale de la Santé. [acessado em 2019 mai. 5]. Disponível em: http://apps. who.int/iris/bitstream/10665/204454/1/zikasitrep_19Feb2016_ eng.pdf?

12. Ribeiro IG, Andrade MR, Silva JM, Silva ZN, Costa MAO, Batista FMA, et al. Microcefalia no Piauí, Brasil: estudo descritivo durante a epidemia do vírus Zika, 2015-2016. Epidemiol. Serv. Saúde. 2018:27(1):e20163692. http://dx.doi.org/10.5123/s167949742018000100002

13. Cruz ACS, Ceccon MEJ. Prevalência de asfixia perinatal e encefalopatia hipóxico-isquêmica em recém-nascidos de termo considerando dois critérios diagnósticos. Rev. Bras. Crescimento Desenvolvimento Hum [Internet]. 2010;20(2):302-16. Disponível em: http://pepsic.bvsalud.org/pdf/rbcdh/v20n2/13.pdf

14. Maciel ELN, Gonçalves EP, Alvarenga VA, Polone CT, Ramos MC. Perfil epidemiológico das malformações congênitas no município de Vitória-ES. Cad Saúde Coletiva [Internet]. 2006;14(3):507-18. Disponível em: http://www.cadernos.iesc.ufrj. br/cadernos/images/csc/2006 3/artigos/ethel maciel.pdf

15. Abreu TT, Novais MCM, Guimarães ICB. Crianças com microcefalia associada a infecção congênita pelo vírus Zika: características clínicas e epidemiológicas num hospital terciário. Rev. Ciênc. Méd. Biol [Internet]. 2016;15(3):426-33. Disponível em: https://periodicos.ufba.br/index.php/cmbio/article/ view/18347/13498
16. Freitas PSS, Soares GB, Mocelin HJS, Lacerda LCX, Prado TN, Sales CMX, et al. Síndrome congênita do vírus Zika: perfil sociodemográfico das mães. Rev Panam Salud Publica. 2019;43:e24. https://doi.org/10.26633/RPSP.2019.24

17. Cajuhi AS, Suto CSS, Mercês AED, Oliveira JSB, Costa LEL, Nascimento RCD, et al. Vivências de cuidadoras sobre o cuidado de crianças com microcefalia. Rev enferm UFPE on line. 2020;14:e243508. https://doi.org/10.5205/1981-8963.2020.243508

18. Costa FAS, Quadrado AVM, Brandão AP, Paes LBA, Carneiro BV, Castanho DLM, et al. Síndrome da Rubéola Congênita: revisão de literatura. Rev Med Saúde [Internet]. 2013;2(1):46-57. Disponível em: https://portalrevistas.ucb.br/index.php/rmsbr/ article/view/3895

19. Woods CG, Parker A. Investigating microcephaly. Arch. Dis. Child. 2013;98:707-13. http://dx.doi.org/10.1136/ archdischild-2012-302882

20. Zanluca C, Melo VCA, Mosimann ALP, Santos GIV, Santos CND, Luz K. First report of autochthonous transmission of Zika virus in Brazil. Mem. Inst. Oswaldo Cruz. 2015;110(4): 569-72. https://doi. org/10.1590/0074-02760150192

21. Albuquerque MFP, Souza WV, Araújo TV, Braga MC, Miranda Filho DB, Ximenes RAA, et al. Epidemia de microcefalia e vírus Zika: a construção do conhecimento em epidemiologia. Cad. Saúde Pública. 2018;34(10):e00069018. https://doi. org/10.1590/0102-311×00069018 